\title{
Correction to: Polypore fungi of Caucasian alder as a source of antioxidant and antitumor agents
}

\author{
Vahide Payamnoor $^{1} \cdot$ Mohammad Reza Kavosi $^{1}$ • \\ Jamile Nazari ${ }^{1}$
}

Published online: 21 July 2020

(C) Northeast Forestry University 2020

\section{Correction to: J. For. Res. (2020) 31(4):1381-1390 https://doi.org/10.1007/s11676-019-00892-2}

In the original publication of the article, the section 'Conclusions' was not included. The paragraph is given below.

\section{Conclusions}

As determined various fungi live on Caucasian Alder trees including Ganoderma applanatum, Lenzites betulina, Trichaptum biforme, Rigidoporus ulamrius, Fomes fomentarius, Schizophyllum commune, Auricularia mesenterica, and Trametes versicolor. The highest amounts of betulin and betulinic acid were obtained in Ganoderma applanatum (3.642\%) and Schizophyllum commune (1.413\%), respectively. The lowest amount of both compounds were in $L$. betulina. All tested fungi had high antioxidant activity. The highest amounts of phenol $(719.993 \mathrm{mg} / \mathrm{ml})$ and flavonoids $(361.403 \mathrm{mg} / \mathrm{ml})$ were found in the ethanolic solvent associated with G. applanatum fungus. It seems that due to high growth rate of fungi, low production cost and the special benefits of betulin and betulinic acid in particular, there is a good prospect for the production of various drugs from these resources.
The original article can be found online at https://doi. org/10.1007/s11676-019-00892-2.

Vahide Payamnoor

mnoori56@gmail.com

1 Gorgan University of Agricultural Sciences and Natural Resources, 098 Gorgan, Golestan, Iran
Publisher's Note Springer Nature remains neutral with regard to jurisdictional claims in published maps and institutional affiliations. 